\title{
Association of HLA-DRB1 polymorphism with Alzheimer's disease: a replication and meta-analysis
}

\author{
Rui-Chun Lu', Wu Yang ${ }^{2}$, Lin Tan ${ }^{1}$, Fu-Rong Sun ${ }^{1}$, Meng-Shan Tan ${ }^{1}$, Wei Zhang ${ }^{1}$, \\ Hui-Fu Wang ${ }^{1}$ and Lan $\operatorname{Tan}^{1}$ \\ ${ }^{1}$ Department of Neurology, Qingdao Municipal Hospital, Qingdao University, Qingdao, China \\ ${ }^{2}$ International Department, The Affiliated Hospital of Qingdao University, Qingdao, China \\ Correspondence to: Lan Tan, email: dr.tanlan@163.com
}

Keywords: Alzheimer's disease, polymorphism, association study, HLA-DRB1, meta-analyses

Received: April 19, $2017 \quad$ Accepted: September 20, $2017 \quad$ Published: October 04, 2017

Copyright: Lu et al. This is an open-access article distributed under the terms of the Creative Commons Attribution License 3.0 (CC BY 3.0 ), which permits unrestricted use, distribution, and reproduction in any medium, provided the original author and source are credited.

\section{ABSTRACT}

Genome-wide association studies (GWAS) have identified one single-nucleotide polymorphism (SNP) rs9271192 within HLA-DRB1 as a risk factor for Alzheimer's disease (AD) in Caucasians. The effect of rs9271192 on AD needed to be verified in other ethnic cohorts. In order to evaluate the association between HLA-DRB1 rs9271192 polymorphism and late-onset AD (LOAD) in the Northern Han Chinese population, we recruited 982 LOAD patients and 1344 sex- and age-matched healthy controls. The results showed that HLA-DRB1 rs9271192 was associated with LOAD (genotype $P=0.015$, allele $P=0.04$ ). The results of logistic regression revealed the $C$ allele homozygosity strongly increased the risk of LOAD under a recessive model in the total sample $(P=0.004, O R=2.069,95 \% C I=1.262-3.434)$. When these data were stratified by apolipoprotein E (APOE) $\varepsilon 4$ status, the observed association was confined to APOE \&4 non-carriers (additive model: $P=0.048$, $O R=1.191,95 \% \mathrm{CI}=1.001-1.417$; recessive model: $P<0.001, O R=2.601,95 \% C I=1.519-4.566)$. Furthermore, metaanalysis after sensitive analysis confirmed that rs9271192 within HLA-DRB1 increased the risk of LOAD (OR $=1.12,95 \% \mathrm{CI}=1.08-1.15)$. To summarize, the $\mathrm{C}$ allele in HLA-DRB1 rs9271192 may be an independent risk factor for LOAD.

\section{INTRODUCTION}

Alzheimer's disease (AD) is a complex and multifactorial neurodegenerative disease $[1,2]$. Recently, increasing researches show that heritability for $\mathrm{AD}$ is high $[3,4]$. In a large twin study suggested that heritability for $A D$ was estimated to be $79 \%$ in the best-fitting model [4]. So far, apolipoprotein $\mathrm{E}(A P O E)$ was unequivocally demonstrated as established susceptibility gene for late-onset $\mathrm{AD}$ (LOAD) $[5,6]$, but the variation of $A P O E$ was not sufficient for the development of the disease. This suggest that there are additional risk loci influence the susceptibility of $\mathrm{AD}$ that remain to be discovered [7]. In recent years, Genome-wide association studies (GWAS) as genetic association studies have shed light on the genetic basis of LOAD, which can discover more several genes and/or loci involved in the susceptibility to suffer this disease $[8,9]$. The meta-analysis of GWAS had been performed in LOAD and tagged HLADRB1 rs9271192 as new susceptibility loci in Caucasians
[10]. Since variants and their frequencies of $H L A-D R B 1$ gene in various ethnic groups might be different, further replication became the urgent task to be performed in other ethnic cohorts [7, 11-15]. Hence, we conducted an association analysis between rs9271192 SNP within HLA-DRB1 and LOAD to verify the above conclusions in the Northern Han Chinese population. Furthermore, there were other two largescale studies investigated an association analysis between rs9271192 SNP within HLA-DRB1 and LOAD in Chinese, did not obtain a consistent conclusion in Chinese. So, we collected our data along with previously studies for metaanalysis to reach a more credible conclusion.

\section{RESULTS}

Replication study

There were no significant differences in gender and age ( $P=0.067, P=0.189$, respectively) between 
AD and controls. Significantly lower Mini Mental State Examination (MMSE) score was found in LOAD patients compared to the controls $(P<0.001)$. As expected, the presence of the $A P O E \varepsilon 4$ allele was associated with of LOAD $(P<0.001)$ (Table 1).

Deviations from distributions of the polymorphisms were excluded by the HWE version 1.20 in both LOAD patients and controls. The allele and genotype frequencies of LOAD patients and controls in the total sample and after stratification for $A P O E \& 4$ allele were shown in Table 2. The rs9271192 polymorphisms in HLA-DRB1 had significant differences in the genotype frequencies in the total sample $(P=0.015)$. And rs9271192 polymorphisms in $H L A-D R B 1$ reached significant differences in the allele frequencies in the total sample $(P=0.04)$. Higher frequencies of the minor allele $(\mathrm{C})$ were observed in patients with LOAD compared with control subjects (19.04\% vs. 16.74\%). When the genotype and allele distribution were stratified by the $A P O E \& 4$ allele status, we observed significant differences in the genotype frequencies in the $A P O E \& 4$ non-carriers $(P=0.002)$. In $A P O E \& 4$ allele carriers, the genotype and allele distribution of rs9271192 between LOAD patients and controls was no significantly different $(P=0.704, P=$ 0.958, respectively). Based on the observed prevalence of the minor alleles in controls, our sample size had greater than $90 \%$ power to detect a relative risk of 1.2 for rs9271192.

We further investigated the distributions of the rs9271192 polymorphism in multivariate logistic regression analysis (adjusted for age, gender, and the $A P O E \& 4$ allele status for the total sample; adjusted for age and gender for the subsets) (Table 3). The results revealed $\mathrm{C}$ allele homozygosity strongly increased the risk of LOAD under a recessive model in the total sample $(P$ $=0.004, \mathrm{OR}=2.069,95 \% \mathrm{CI}=1.262-3.434)$. We further evaluated the association of rs9271192 with LOAD risk in patients with or without $A P O E \varepsilon 4$ allele using logistic regression in order to rule out confounding factors in the subsets. As indicated by Table 3, in non- $A P O E \& 4$ carriers, the $\mathrm{C}$ allele at rs9271192 increased LOAD risk in additive model and recessive model (additive model: $P=0.048$, $\mathrm{OR}=1.191,95 \% \mathrm{CI}=1.001-1.417$; recessive model: $P<$ $0.001, \mathrm{OR}=2.601,95 \% \mathrm{CI}=1.519-4.566)$.

\section{Meta-analysis}

The initial search on computerized databases screened 19 articles. After 16 articles were excluded due to no correlation to rs9271192 or Alzheimer's disease, observational studies, editorials or reviews, 3 eligible articles were found (Figure 1). We extracted the data of different populations from the three large studies [9, $16,17]$ and ours, then regrouped them according to Caucasians and Chinese as subgroup for meta-analysis. We found there was a high heterogeneity $\left(\mathrm{I}^{2}=79.8 \%\right)$ in the Chinese subgroup (Figure 2). Thus, we carried out the sensitivity analysis and found that the heterogeneity significantly declined when excluding the study of Jiao et al. [17]. There is no obvious heterogeneity (Caucasians subgroup: $\mathrm{I}^{2}=12.2 \%$, Chinese subgroup: $\left.\mathrm{I}^{2}=0.0 \%\right)$ in the two subgroups (Figure 3). Finally, we found the less frequent allele (C allele) at rs9271192 was risk factor for LOAD in Caucasians $(\mathrm{OR}=1.11,95 \% \mathrm{CI}=1.08-1.15)$ and Chinese $(\mathrm{OR}=1.18,95 \% \mathrm{CI}=1.02-1.36)$ (Figure 3). Notably, our study found rs9271192 showed significant association with LOAD in pooled populations $(\mathrm{OR}=1.12$, $95 \% \mathrm{CI}=1.08-1.15$ ) (Figure 3 ) without evident analysis heterogeneity $\left(\mathrm{I}^{2}=6.4 \%\right)$.

\section{DISCUSSION}

In our current study, there was statistically significant evidence for the $H L A-D R B 1$ genotype $\mathrm{CC}$ as risk factors to LOAD in the Northern Han Chinese population (recessive model: $P=0.004$, OR $=2.069$, $95 \%$ CI $=1.262-3.434)$. Moreover, we also found that non- $A P O E \& 4$ carriers with rs9271192 genotype CC had a significantly higher risk of LOAD than those with the genotype $\mathrm{CA}+\mathrm{AA}$ (recessive model: $P<0.001$, $\mathrm{OR}=$ $2.601,95 \% \mathrm{CI}=1.519-4.566)$. In contrast, $A P O E \varepsilon 4$ carriers with rs9271192 genotype $\mathrm{CC}$ did not have a higher risk than the other $A P O E \varepsilon 4$ carriers (recessive model: $P=$ $0.430, \mathrm{OR}=0.629,95 \% \mathrm{CI}=0.193-2.048)$. The possible interpretation is that the genetic effect of $H L A-D R B 1$ is predisposing factor to LOAD in the absence of the $A P O E$ $\varepsilon 4$ allele, while $A P O E \varepsilon 4$ allele is the most susceptible genetic factor in $A P O E \& 4$ carriers [18].

Furthermore, the effects of some genetic variants confirmed by GWAS in various ethnic groups might be different, due to population-specific and some unknown gene-gene or gene-environment interactions. To avoid these possibly complicated reasons and further investigate these associations, meta-analysis was performed in Caucasians and Chinese. We found there was a high heterogeneity $\left(\mathrm{I}^{2}=79.8 \%\right)$ in the Chinese subgroup. There were two following researches made different conclusions in Chinese [16, 17]. Xiao et al. found no significant association between rs9271192 and $\mathrm{AD}(\mathrm{OR}=1.30,95 \%$ $\mathrm{CI}=0.91-1.85, \mathrm{P}=0.144)$. Jiao et al. drew diametrically opposite conclusion that C allele in HLA-DRB1 rs9271192 on $\mathrm{AD}$ was found to be associated with decreasing LOAD risk $(\mathrm{OR}=0.703,95 \% \mathrm{CI}=0.521-0.949, P=0.021)$. The different sample sizes, many unknown demographic, clinical variables and possibility of false positives might attribute to the different results. When we carried out the sensitivity analysis and excluded the study of Jiao et al. [17], the heterogeneity significantly declined $\left(\mathrm{I}^{2}=0.0 \%\right)$. Finally, the results of meta-analysis showed that the $\mathrm{C}$ allele in HLA-DRB1 rs9271192 may be an independent risk factor for LOAD, and the result coincided with the recent large-scale GWAS and our study. 
Table 1: The characteristics of the study population

\begin{tabular}{|c|c|c|c|c|c|c|c|c|c|c|}
\hline & & & \multicolumn{2}{|c|}{$\mathrm{AD}(n=982)$} & \multicolumn{3}{|c|}{ Control $(n=1344)$} & $P$ value & \multicolumn{2}{|c|}{ OR $(95 \% \mathrm{CI})$} \\
\hline \multicolumn{3}{|c|}{ Age at examination, years; mean $\pm \mathrm{SD}$} & \multicolumn{2}{|c|}{$79.83 \pm 6.69$} & \multicolumn{3}{|c|}{$75.49 \pm 6.48$} & $0.189^{*}$ & & \\
\hline \multicolumn{3}{|c|}{ Age at onset, years; mean $\pm \mathrm{SD}$} & \multicolumn{2}{|c|}{$75.17 \pm 6.08$} & & & & & & \\
\hline \multicolumn{3}{|c|}{ Gender, $n(\%)$} & & & & & & 0.067 & & \\
\hline \multicolumn{3}{|l|}{ Male } & \multicolumn{2}{|c|}{$408(41.50)$} & \multicolumn{3}{|c|}{$596(44.30)$} & & & \\
\hline Female & & & \multicolumn{2}{|c|}{$574(58.50)$} & \multicolumn{3}{|c|}{$748(55.70)$} & & & \\
\hline \multicolumn{3}{|c|}{ MMSE score, mean \pm SD } & \multicolumn{2}{|c|}{$11.94 \pm 6.21$} & \multicolumn{3}{|c|}{$28.49 \pm 1.09$} & \multicolumn{3}{|l|}{$<0.001$} \\
\hline \multicolumn{5}{|c|}{ APOE $\varepsilon 4$ status, $n(\%)$} & \multirow{2}{*}{\multicolumn{4}{|c|}{$189(14.10)$}} & \multirow{3}{*}{\multicolumn{2}{|c|}{$2.45(2.00-3.01)$}} \\
\hline APOE $\varepsilon$ & & & \multicolumn{2}{|c|}{$280(28.60)$} & & & & & & \\
\hline APOE $\varepsilon$ & & & & & \multicolumn{3}{|c|}{$1155(85.90)$} & & & \\
\hline \multicolumn{11}{|c|}{$\begin{array}{l}\text { Abbreviation: AD, Alzheimer's disease; Control, healthy controls; OR, odds ratio; CI, confidence interval; MMSE, Mini- } \\
\text { Mental State Examination; APOE, apolipoprotein E; SD, standard deviation. } \\
{ }^{*} P \text { value was calculated with the age of onset for late-onset AD and age at examination for Control. Differences in the } \\
\text { characteristics of age and MMSE score between the two groups were examined using Student's } t \text { test. Differences in gender } \\
\text { and APOE } \varepsilon 4 \text { frequency between AD patients and Control were assessed using the Pearson } \chi^{2} \text { test. }\end{array}$} \\
\hline \multicolumn{11}{|c|}{$\begin{array}{l}\text { Table 2: Distribution of the rs } 7294919 \text { genotypes and alleles in AD cases and controls stratified } \\
\text { by } A P O E \& 4 \text { presence }\end{array}$} \\
\hline \multirow[t]{2}{*}{ Total } & $N$ & \multicolumn{3}{|c|}{ Genotype } & & $P$ & \multicolumn{3}{|c|}{ Allele } & \multirow[t]{2}{*}{$P$} \\
\hline & & $\mathrm{CC}(\%)$ & $\mathrm{CA}(\%)$ & & & & & $(\%)$ & $\mathrm{A}(\%)$ & \\
\hline$\overline{\mathrm{AD}}$ & 982 & $40(4.07)$ & $294(29.93)$ & & & $0.015^{*}$ & & $(19.04)$ & $1590(80.96)$ & $0.04^{*}$ \\
\hline Controls & 1344 & $28(2.08)$ & $394(29.32)$ & 922 & $60)$ & & & $(16.74)$ & $2238(83.26)$ & \\
\hline \multicolumn{11}{|c|}{ APOE $84(+)$} \\
\hline $\mathrm{AD}$ & 280 & $6(2.14)$ & $96(34.29)$ & 178 & $.57)$ & 0.70 & & $(19.29)$ & $452(80.71)$ & 0.96 \\
\hline Controls & 188 & $6(3.19)$ & $60(31.92)$ & 122 & $.89)$ & & & 19.15) & $304(80.85)$ & \\
\hline \multicolumn{11}{|c|}{ APOE $\varepsilon 4(-)$} \\
\hline $\mathrm{AD}$ & 702 & $34(4.84)$ & $198(28.21)$ & 470 & $.95)$ & $0.002^{*}$ & & (18.95) & 1138 (81.05) & 0.86 \\
\hline Controls & 1156 & $22(1.90)$ & 334 (28.89) & 800 & $.21)$ & & & $(16.35)$ & $1934(83.65)$ & \\
\hline
\end{tabular}

Notes: AD, Alzheimer's disease; APOE $\varepsilon 4(+)$ subjects who had 1 or $2 \varepsilon 4$ alleles; APOE $\varepsilon 4(-)$ subjects who did not have the $\varepsilon 4$ allele; $\mathrm{CI}$, confidence interval; $\mathrm{OR}$, odds ratio; $\mathrm{P}, P$ value.

* Mean $P \leq 0.05$.

The SNP rs9271192 locate at the 20917bp site upstream of the transcription start point of the $H L A-D R B 1$. And the $H L A-D R B 1$ has a highly polymorphic region located on chromosome 6 associated with immunocompetence and histocompatibility, which is responsible for numerous immune responses [19]. Meanwhile, immune activation and possibly inflammation in the brain could play a remarkable role in the pathogenesis of $\mathrm{AD}$ were highlighted in numerous reports [20, 21]. Moreover, recent large-scale assessment of genetic risk factors associated with Parkinson's disease (PD) identified HLA-DRB5 as novel risk loci [22]. PD and AD both are proteinopathy which characterized by neurodegeneration resulting from abnormal protein aggregation [23]. Given the association of this locus with PD, HLA-DRB1 may also have a similar role in inflammatory responses that contribute to AD. All the above, we could hypothesize that inflammatory mechanisms could contribute to the pathophysiology of AD. However, Yu et al. had found that the methylation of $H L A$ $D R B 5$ was only nominal association with pathological $\mathrm{AD}$ diagnosis [24]. Hence, further biology evidence of HLA$D R B 1$ from independent studies need to be warranted.

In summary, our current study has provided a convincing statistical support for an association between the HLA-DRB1 polymorphism and LOAD, the carriage of $\mathrm{C}$ allele of the rs 9271192 is associated with increased risk of LOAD in a Northern Han Chinese population. In the future, more studies in more large cohorts and in other ethnic groups are needed to validate the role of rs9271192 in LOAD. Furthermore, the additional independent replications and functional genetic analyses should elucidate the potential pathological mechanisms and the epidemiologic relevance of $H L A-D R B 1$ gene in AD. 
Table 3: Logistic regression analysis of rs9271192 SNP in $H L A-D R B 1$ gene

\begin{tabular}{lcccc}
\hline SNP & Group & Model & OR (95\% CI) & P \\
\hline rs9271192 & Total $^{\mathrm{a}}$ & Add & $1.147(0.981-1.340)$ & 0.085 \\
& & Dom & $1.088(0.910-1.301)$ & 0.355 \\
& Rec & $2.069(1.262-3.434)$ & $0.004^{*}$ \\
& APOE\&4 $(+)^{\mathrm{b}}$ & Add & $0.992(0.702-1.407)$ & 0.962 \\
& Dom & $1.042(0.707-1.542)$ & 0.834 \\
& Rec & $0.629(0.193-2.048)$ & 0.430 \\
& APOE\&4 $(-)^{\mathrm{b}}$ & Add & $1.191(1.001-1.417)$ & $0.048^{*}$ \\
& & Dom & $1.105(0.903-1.350)$ & 0.332 \\
& Rec & $2.601(1.519-4.566)$ & $<0.001^{*}$ \\
\hline
\end{tabular}

Notes: CI, confidence interval; OR, odds ratio; P, $P$ value; Add, additive model; Dom, dominant model; Rec, recessive model;

${ }^{\text {a }}$ Adjusted for age, gender, and the carriage of at least one $A P O E \varepsilon 4$ allele.

${ }^{\mathrm{b}} A P O E \varepsilon 4(+) / A P O E \varepsilon 4(-)$ subset: adjusted for age and gender.

* Mean $P \leq 0.05$.

\section{MATERIALS AND METHODS}

\section{Subjects}

Our study investigated 2326 subjects including 982 LOAD patients (mean age at onset: $75.17 \pm 6.08$ years; 584 women) and 1344 healthy control subjects (mean age at examination: $75.49 \pm 6.48 ; 748$ women) matched for gender and age. All the subjects in our study were unrelated Northern Han Chinese residents from Shandong province. The patients were assembled from the Department of Neurology of Qingdao Municipal Hospital and several other hospitals in Shandong. The subjects in case group were clinically diagnosed as "probable AD" by at least 2 neurologists, which according to the criteria of the National Institute of Neurological and Communicative Disorders and Stroke and/or Alzheimer's Disease and Related Disorders Association (NINCDS/ADRDA) [25]. The AD patients had no family history of neurodegenerative disorders or other dementias that were recruited in the case group. The control group was collected from the Healthy Examination Center of the Qingdao Municipal Hospital and at least two neurologists confirmed them healthy and neurologically normal by medical history, general examinations, laboratory examination, and MMSE score $\geq 28$. The informed consent of this study was acquired from all subjects or their guardians, and our study was carried out with approval by the Institutional Ethics Committees. Our study was conducted with approval from the Ethical Committee of Qingdao Municipal Hospital.

\section{Genotyping analysis}

Genomic DNA was extracted from the peripheral blood leukocytes by standard procedures using the Wizard genomic DNA purification kit (Cat. \#A1125, Promega,
USA). Genotyping for the HLA-DRB1 (rs9271192) was carried out by a patent-pending technology of SNP scan which was developed on double ligation and multiplex fluorescence PCR from Genesky Biotechnologies Inc. Randomly selected DNA samples from each genotype were sequenced to validate the genotyping by ligation detection reaction method, and the case status of study subjects was blind to the laboratory staff. Results of the ligation detection reaction method corresponded with the results of sequencing.

\section{Statistical analysis}

HWE version 1.20 (Columbia University, New York, NY, USA) was used to exclude deviations from Hardy-Weinberg equilibrium (HWE). Differences in the characteristics of the study subjects between the two groups were examined using the Student $t$ test or the Chi-square test. Genotype and allele distributions were compared in the two groups by using the $\mathrm{x}^{2}$ test. A binary logistic regression model, adjusted for age (age at examination for control subjects), gender and $A P O E \& 4$ status, was used to estimate ORs and the $95 \%$ confidence interval (CI) for testing possible associations between SNPs and AD. We defined various genetic models as $\mathrm{AA}$ vs. $(\mathrm{CA}+\mathrm{CC})$ for dominant, $\mathrm{CC}$ vs. $(\mathrm{CA}+\mathrm{AA})$ for recessive, and $\mathrm{CC}$ vs. AA for additive. The statistical power was calculated by STPLAN 4.5 software.

\section{Meta-analyses}

\section{Search strategy}

We carried out a systematic literature search of MEDLINE, EMBASE and the Cochrane library for studies published in the period from January 1995 to January 2016 to investigate the association between the $H L A-D R B 1$ rs9271192 polymorphism and AD. The key 
search terms including HLA-DRB1, HLA-DRB5-DRB1, rs9271192, Alzheimer's disease, and AD, combined with Boolean operators as appropriate. There were no language restrictions in our research. The reference lists of relevant primary articles were the source of additional studies.

\section{Study selection}

The adopted articles were in accord to the following criteria: (1) case-control studies design; (2) Patients were included if they met the NINCDS-ADRDA criteria for AD diagnosis; (3) data of the ORs with corresponding 95\% CIs were available in the report or could be calculated. Reviews, editorials, articles without essential data, and papers focused on familial AD were eliminated. Additionally, we only selected the data from the most comprehensive report for the meta-analysis if there was more than one publication from the same population.

\section{Data extraction and quality assessment}

Two reviewers cooperated to accomplish data abstraction which was blinded to the authors and journal.
Discrepancies in the collected data were discussed with other team members or contact with original investigators. If consensus was not reached, a third reviewer decided the final result. Once data of the ORs with corresponding $95 \%$ CIs could not extract directly, we sought them from the authors. We tried to seek the missing information and essential clarification from the original authors. According to the data of each qualified study, we extracted the ORs with corresponding $95 \%$ CIs from logistic regression. The study quality was assessed with the Newcastle-Ottawa Quality Scale (NOS). Our studies were considered highquality, with a score of at least seven points.

\section{Statistical analysis}

We pooled our data with the results from metaanalysis of 82501 individuals [9] and other reports about $H L A-D R B 1$ (rs9271192) and LOAD $[16,17]$ by fixedeffects inverse variance-weighted methods. We also generated $\mathrm{I}^{2}$ estimates with evaluate the possible effect of study heterogeneity on the results $\left(\mathrm{I}^{2}<50 \%\right.$, mean a lack of heterogeneity among populations). Our studies used Stata V.12.0 to perform all the meta-analyses.

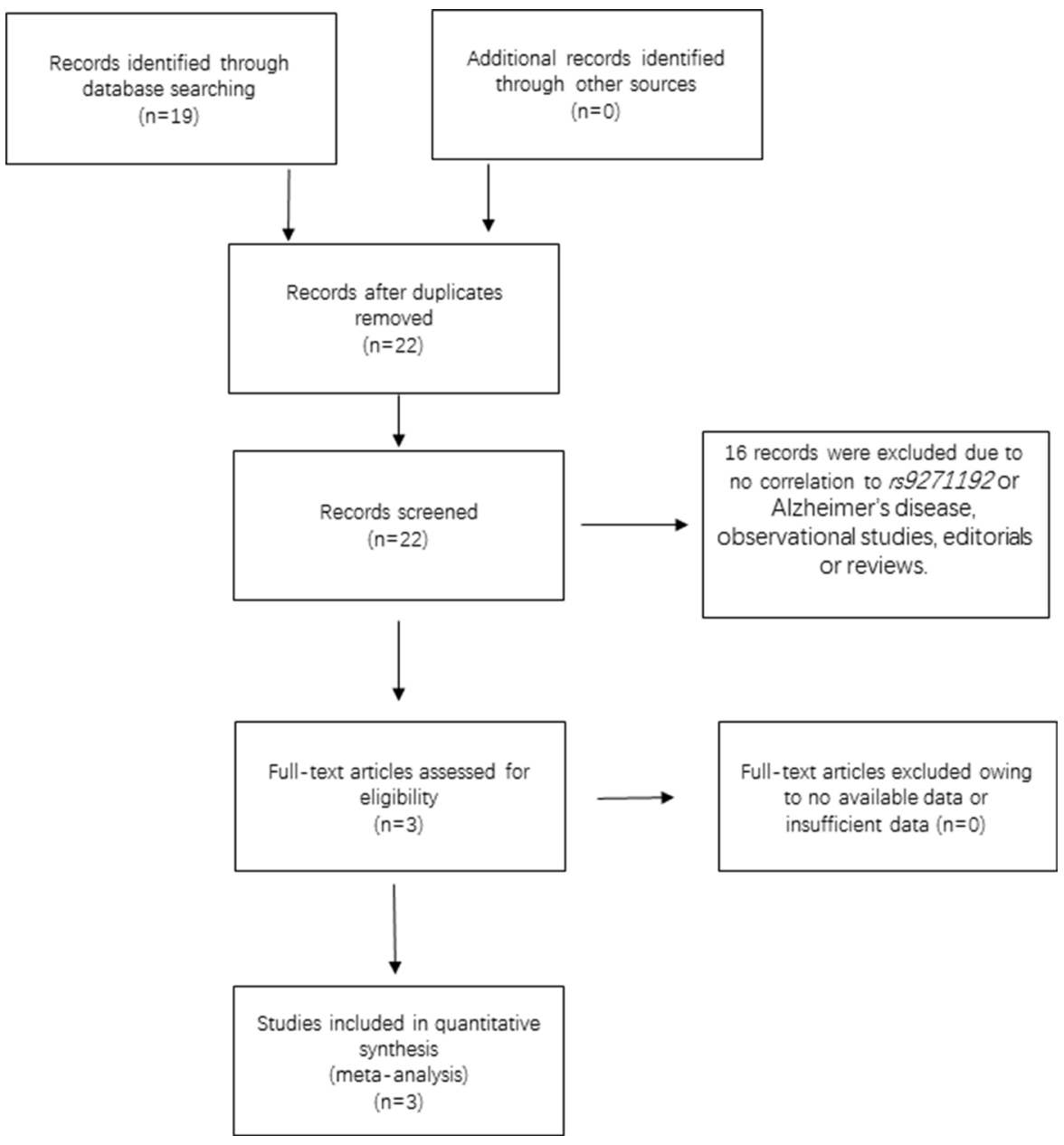

Figure 1: Flow chart of the search strategy and study selection. 


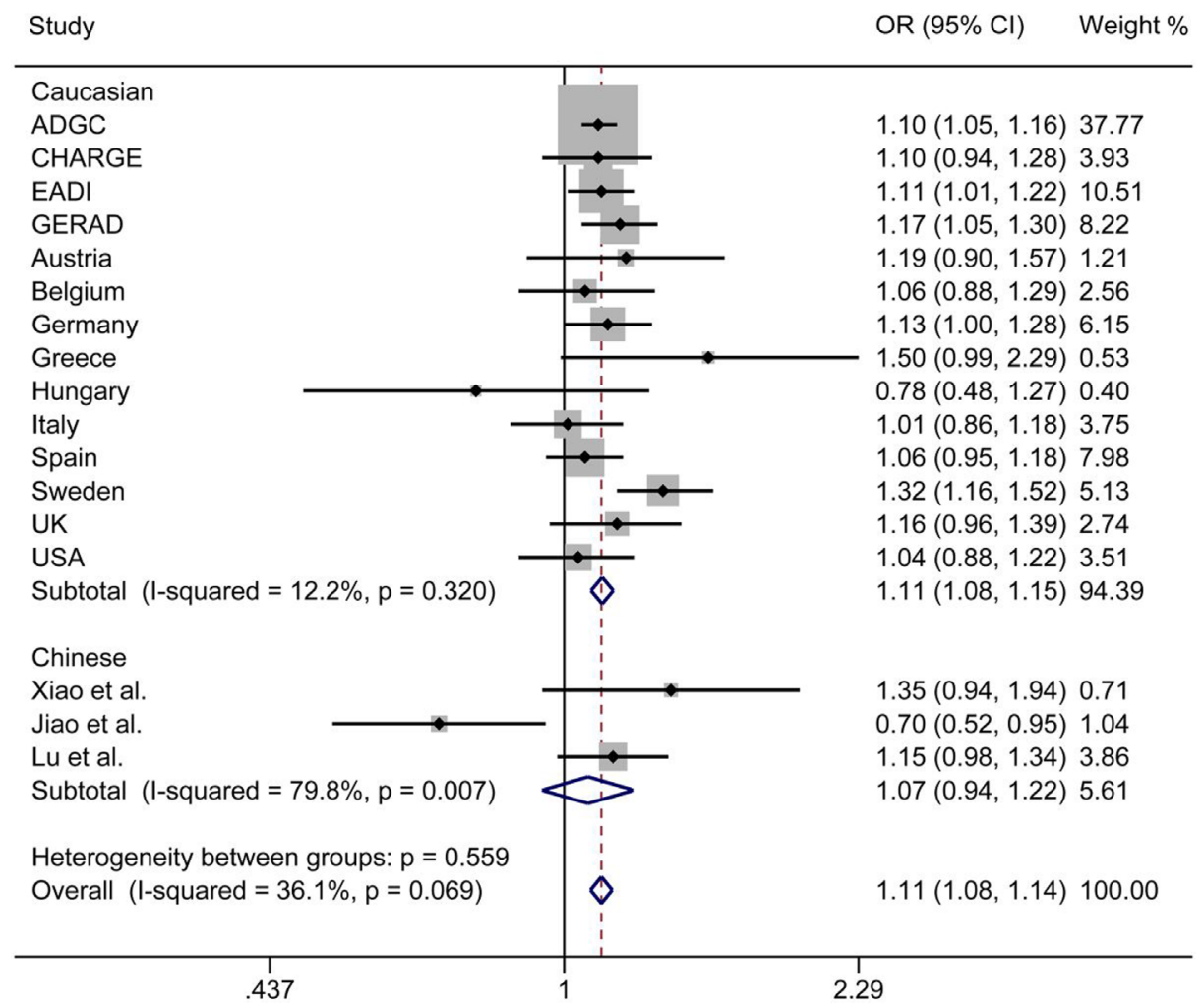

Figure 2: Forest plots for rs9271192 in LOAD and healthy controls in 82501 individuals, which show the association by ethnicity. There was a high heterogeneity in the Chinese subgroup $\left(I^{2}=79.8 \%\right)$. OR: odds risk, CI: confidence interval.

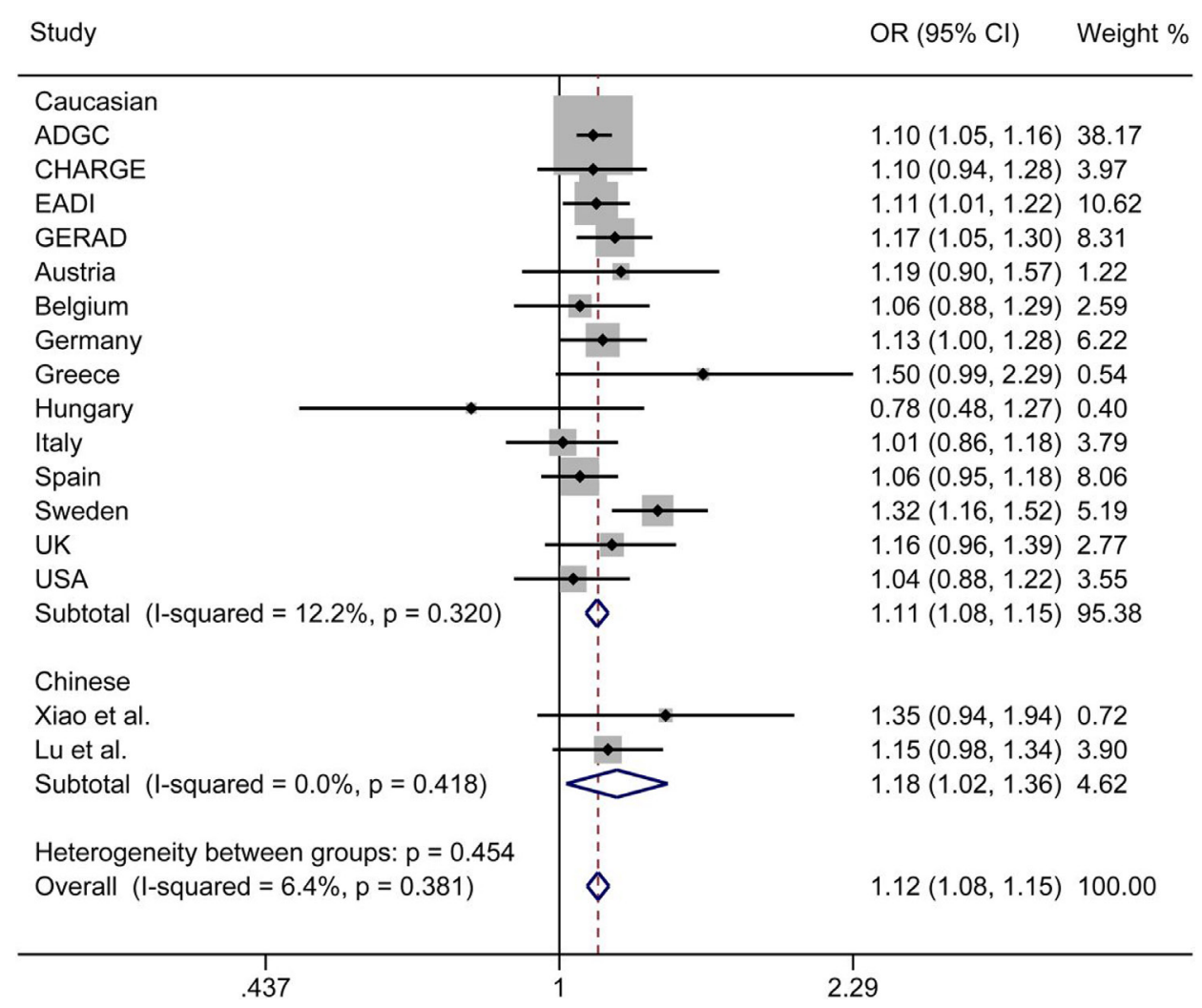

Figure 3: Forest plots for rs9271192 in LOAD and healthy controls in 81954 individuals, which show the association by ethnicity. The heterogeneity significantly declined when excluding the Jiao et al. study. OR: odds risk, CI: confidence interval. 


\section{ACKNOWLEDGMENTS AND FUNDING}

This work was supported by grants from the National Natural Science Foundation of China (81471309, 81371406, 81571245, and 81501103), the Shandong Provincial Outstanding Medical Academic Professional Program, Qingdao Key Health Discipline Development Fund, Qingdao Outstanding Health Professional Development Fund, and Shandong Provincial Collaborative Innovation Center for Neurodegenerative Disorders.

\section{CONFLICTS OF INTEREST}

The authors disclose no conflicts of interest.

\section{REFERENCES}

1. Guerini FR, Tinelli C, Calabrese E, Agliardi C, Zanzottera M, De Silvestri A, Franceschi M, Grimaldi LM, Nemni $\mathrm{R}$, Clerici M. HLA-A*01 is associated with late onset of Alzheimer's disease in Italian patients. Int J Immunopathol Pharmacol. 2009; 22:991-999.

2. Cifuentes RA, Murillo-Rojas J. Alzheimer's disease and HLA-A2: linking neurodegenerative to immune processes through an in silico approach. Biomed Res Int. 2014; 2014:791238.

3. Cruchaga C, Haller G, Chakraverty S, Mayo K, Vallania FL, Mitra RD, Faber K, Williamson J, Bird T, Diaz-Arrastia R, Foroud TM, Boeve BF, Graff-Radford NR, et al. Rare variants in APP, PSEN1 and PSEN2 increase risk for AD in late-onset Alzheimer's disease families. PloS one. 2012; 7:e31039.

4. Gatz M, Reynolds CA, Fratiglioni L, Johansson B, Mortimer JA, Berg S, Fiske A, Pedersen NL. Role of genes and environments for explaining Alzheimer disease. Arch Gen Psychiat. 2006; 63:168-174.

5. Hauser PS, Ryan RO. Impact of apolipoprotein E on Alzheimer's disease. Curr Alzheimer Res. 2013; 10:809-817.

6. Jiang T, Yu JT, Wang YL, Wang HF, Zhang W, Hu N, Tan L, Sun L, Tan MS, Zhu XC, Tan L. The genetic variation of ARRB2 is associated with late-onset Alzheimer's disease in Han Chinese. Curr Alzheimer Res. 2014; 11:408-412.

7. Xia M, Yu JT, Miao D, Lu RC, Zheng XP, Tan L. SIRT2 polymorphism rs10410544 is associated with Alzheimer's disease in a Han Chinese population. J Neurol Sci. 2014; 336:48-51.

8. Naj AC, Jun G, Beecham GW, Wang LS, Vardarajan BN, Buros J, Gallins PJ, Buxbaum JD, Jarvik GP, Crane PK, Larson EB, Bird TD, Boeve BF, et al. Common variants at MS4A4/MS4A6E, CD2AP, CD33 and EPHA1 are associated with late-onset Alzheimer's disease. Nat Genet. 2011; 43:436-441.

9. Hollingworth P, Harold D, Sims R, Gerrish A, Lambert JC, Carrasquillo MM, Abraham R, Hamshere ML, Pahwa
JS, Moskvina V, Dowzell K, Jones N, Stretton A, et al. Common variants at ABCA7, MS4A6A/MS4A4E, EPHA1, CD33 and CD2AP are associated with Alzheimer's disease. Nat Genet. 2011; 43:429-435.

10. Lambert JC, Ibrahim-Verbaas CA, Harold D, Naj AC, Sims R, Bellenguez C, DeStafano AL, Bis JC, Beecham GW, Grenier-Boley B, Russo G, Thorton-Wells TA, Jones N, et al. Meta-analysis of 74,046 individuals identifies 11 new susceptibility loci for Alzheimer's disease. Nat Genet. 2013; 45:1452-1458.

11. Yu JT, Song JH, Ma T, Zhang W, Yu NN, Xuan SY, Tan L. Genetic association of PICALM polymorphisms with Alzheimer's disease in Han Chinese. J Neurol Sci. 2011; 300:78-80.

12. Yu JT, Miao D, Cui WZ, Ou JR, Tian Y, Wu ZC, Zhang W, Tan L. Common variants in toll-like receptor 4 confer susceptibility to Alzheimer's disease in a Han Chinese population. Curr Alzheimer Res. 2012; 9:458-466.

13. Wang W, Yu JT, Zhang W, Cui WZ, Wu ZC, Zhang Q, Tan L. Genetic association of SLC2A14 polymorphism with Alzheimer's disease in a Han Chinese population. J Mol Neurosci. 2012; 47:481-484.

14. Wang HF, Tan L, Yu JT, Ma XY, Liu QY, Wang W. Agedependent association of KIBRA gene polymorphism with Alzheimer's disease in Han Chinese. Mol Biol Rep. 2013; 40:7077-7082.

15. Zhang J, Li Y. SLC26A4 gene polymorphism and late-onset Alzheimer's disease in a Han Chinese population from Qingdao, China. Neural Regen Res. 2013; 8:754-759.

16. Xiao Q, Liu ZJ, Tao S, Sun YM, Jiang D, Li HL, Chen H, Liu X, Lapin B, Wang CH, Zheng SL, Xu J, Wu ZY. Risk prediction for sporadic Alzheimer's disease using genetic risk score in the Han Chinese population. Oncotarget. 2015; 6:36955-36964. http://doi.org/10.18632/oncotarget.6271.

17. Jiao B, Liu X, Zhou L, Wang MH, Zhou Y, Xiao T, Zhang W, Sun R, Waye MM, Tang B, Shen L. Polygenic Analysis of Late-Onset Alzheimer's Disease from Mainland China. PloS one. 2015; 10:e0144898.

18. Nacmias B, Tedde A, Bagnoli S, Cellini E, Guarnieri BM, Piacentini S, Sorbi S. Implication of GAB2 gene polymorphism in Italian patients with Alzheimer's disease. J Alzheimers Dis. 2009; 16:513-515.

19. Lehmann DJ, Wiebusch H, Marshall SE, Johnston C, Warden DR, Morgan K, Schappert K, Poirier J, Xuereb J, Kalsheker N, Welsh KI, Smith AD. HLA class I, II \& III genes in confirmed late-onset Alzheimer's disease. Neurobiol Aging. 2001; 22:71-77.

20. Shadfar S, Hwang CJ, Lim MS, Choi DY, Hong JT. Involvement of inflammation in Alzheimer's disease pathogenesis and therapeutic potential of anti-inflammatory agents. Arch Pharm Res. 2015; 38:2106-19.

21. Serpente M, Bonsi R, Scarpini E, Galimberti D. Innate immune system and inflammation in Alzheimer's disease: from pathogenesis to treatment. Neuroimmunomodulat. $2014 ; 21: 79-87$. 
22. International Parkinson Disease Genomics Consortium, Nalls MA, Plagnol V, Hernandez DG, Sharma M, Sheerin UM, Saad M, Simon-Sanchez J, Schulte C, Lesage S, Sveinbjornsdottir S, Stefansson K, Martinez M, et al. Imputation of sequence variants for identification of genetic risks for Parkinson's disease: a meta-analysis of genomewide association studies. Lancet. 2011; 377:641-649.

23. Tsigelny IF, Crews L, Desplats P, Shaked GM, Sharikov Y, Mizuno H, Spencer B, Rockenstein E, Trejo M, Platoshyn O, Yuan JX, Masliah E. Mechanisms of hybrid oligomer formation in the pathogenesis of combined Alzheimer's and Parkinson's diseases. PloS one. 2008; 3:e3135.
24. Yu L, Chibnik LB, Srivastava GP, Pochet N, Yang J, Xu J, Kozubek J, Obholzer N, Leurgans SE, Schneider JA, Meissner A, De Jager PL, Bennett DA. Association of Brain DNA methylation in SORL1, ABCA7, HLA-DRB5, SLC24A4, and BIN1 with pathological diagnosis of Alzheimer disease. JAMA Neurol. 2015; 72:15-24.

25. McKhann G, Drachman D, Folstein M, Katzman R, Price D, Stadlan EM. Clinical diagnosis of Alzheimer's disease: report of the NINCDS-ADRDA Work Group under the auspices of Department of Health and Human Services Task Force on Alzheimer's Disease. Neurology. 1984; 34:939-944. 